\title{
Assess Knowledge and Attitudes on First-Aid Measures for Selected Domestic Accidents among Caretakers of Under-Five Children
}

\author{
Pushplata Manta $^{1}$, Kanu Mahajan ${ }^{2}$, Kanika Guleria ${ }^{3}$ \\ ${ }^{1}$ Nursing Tutor, ${ }^{2}$ Nursing Tutor, ${ }^{3}$ Assistant Professor, Chitkara School of Health Sciences, \\ Chitkara University Punjab
}

\begin{abstract}
Background: Mishaps are one of the fifth driving reasons for death in industrialized and creating nations. Wounds emerging from mishaps are an expanding general medical issue. Mishaps are a noteworthy reason for dreariness and mortality in kids.
\end{abstract}

Objectives: The present study was undertaken to find out the knowledge level of women regarding domestic accidents among children.

Method: A descriptive comparative research design was used for the present study. A study sample of 100 care takers of under- five children (50 residing in rural area and 50 residing in urban area) were selected with help of purposive sampling method. Structured questionnaire was used to assess the knowledge and Likert scale was used to find out the attitude regarding first aid measures regarding selected domestic accidents among under five children.

Results: In rural area maximum numbers of care takers had average knowledge regarding domestic accidents i.e. $74 \%, 22 \%$ had good knowledge and $4 \%$ had below average. Where as in urban area maximum numbers of care takers had average knowledge regarding domestic accidents i.e. $62 \%, 33 \%$ had good knowledge and $8 \%$ had below average. In rural area maximum numbers of care takers had undecided attitude regarding domestic accidents i.e. $64 \%, 36 \%$ had strongly disagree attitude and $0 \%$ had strongly agree attitude regarding statements. Where as in urban area maximum numbers of care takers had undecided attitude regarding domestic accidents i.e. $78 \%, 20 \%$ had strongly disagree attitude and $2 \%$ had strongly agree attitude regarding statements.

Conclusion: The study findings concluded that majority of care takers have average knowledge and undecided attitude towards domestic accidents of under five children. So, the researcher provides the information booklet to enhance and improve knowledge and attitude of care takers towards domestic accidents.

Keywords: Mothers, Age, Education, Occupation, Socio-Economic Status.

\section{Introduction}

In this day and age, in the created just as the creating nations, risk wins on the streets, yet it likewise exists in the home and play areas. Consistently, a large number of kids pass on or for all time incapacitated because of inadvertent wounds. In many creating nations, wounds are one of the real reasons for death in youngsters in the age gathering of 1-5 years. Childrenbrea the life into scent and significance, they are an endowment of god and we are the planters to address their issues, we give the best to them by appropriate consideration, sustenance, love, consideration and great wellbeing. ${ }^{(1)}$ It is evaluated that number of passing from residential accidents and injuries in 2005 would extend from 730,000 to 985,000 with projections that passing from wounds will increment by as much as $25 \%$ throughout the following decade. ${ }^{(2)}$ The damage mortality gauges for the year 2002 recommend that about $9 \%$ of all passing in India, 
were represented by all wounds share like the worldwide portion of passing because of wounds. Accessible proof from India likewise demonstrates that a great part of the mortality from wounds because of mishaps, murder more kids.

Material and Method: Quantative research approach with descriptive comparative research design was adopted to accomplish the objective of the study that is to estimate the knowledge and attitude level on first-aid measures regarding selected domestic accidents among caretakers of under-five children in selected rural and urban areas of District Fatehgarh Sahib, Punjab.

Ethical clearance was obtained from ethical committee of Desh Bhagat University, Mandi Gobindgarh to conduct the study. Written permission had been taken from Municipal committee of Amloh Shansi Mohalla (Urban Area) and Jalalpur and Baronga Buland of (rural area). Confidentiality and anonymity of the study subjects was maintained.

Permission letter was taken from Director of DBUSON and Sarpanch Baronga and Jalalpur of (rural area) and Municipal committee of Amloh (urban area). The study was conducted on a sample of 100 care takers who were selected by using Non-probability purposive sampling technique, out of which 50 care takers were selected from rural area and 50 care takers were selected from urban area of district Fatehgarh Sahib. The demographic Performa sheet was filled by care takers. A self-structured questionnaire was administered to sample to assess their knowledge level regarding domestic accidents of under- five children. Likert scale performa was administer to assess the attitude of care takers regarding domestic accidents.

\section{Results}

A total 100 samples were interviewed in this study. The knowledge regarding domestic accidents in family were In rural area. maximum Education of care takers $(54 \%)$ was primary education followed by $(42 \%)$ was matric and (4\%) was secondary education whereas in urban area education of care takers $(58 \%)$ was primary education, (34\%) was matric followed by (4\%) was secondary and (4\%) was graduate and above. According to family income of the maximum care takers in rural area (66\%) had family income below 10,000 followed by (30\%) had family income Rs $10000-20000$, (4\%) had more than and equal to Rs 30,000 , whereas the maximum family income of care takers of under five children in urban area (34\%) had family income between $20,000-30,000$ followed by (26\%) had family income below equal to Rs $10000,(22 \%)$ had more than and equal to Rs 30,000 and above followed by the (18\%) had Rs 10000-20000. . Maximum care takers of under five children in rural area (46\%) had gained information from media followed by (30\%) had gained information from relatives, $(24 \%)$ had gained information from health personals, whereas in urban area $(78 \%)$ had gained information from media and followed by $(10 \%)$ had gained information from any other source, $(8 \%)$ had gained information from mass relatives $(4 \%)$ from health personals. According to type of accident maximum in rural area had not met any type of accident (82\%) $(18 \%)$ have met type of accident. Where as in urban area (20\%) had accident followed by $(80 \%)$ do not have any accident.

Table 1: Criterion Measure of knowledge Score among care takers residing in Rural Area and Urban Area $N=100 n_{r}=50 n_{u}=50$

\begin{tabular}{|l|c|c|c|c|}
\hline \multirow{2}{*}{ Level of knowledge } & \multicolumn{2}{|c|}{ Rural Area } & \multicolumn{2}{c|}{ Urban Area } \\
\cline { 2 - 5 } & (f) & $\mathbf{( \% )}$ & (f) & (\%) \\
\hline Good (21-30) & 11 & 22 & 15 & 30 \\
\hline Average (11-20) & 37 & 74 & 31 & 62 \\
\hline Below Average (0-10) & 02 & 04 & 04 & 08 \\
\hline
\end{tabular}

Maximum Knowledge score: 1

Minimum Knowledge score: 0

Table 1 depicted the level of knowledge score among care takers residing in Rural area(22\%) had good level of knowledge followed by (74\%) had average level of knowledge, followed by (04\%) had below average knowledge whereas in urban area $(30 \%)$ had good level of knowledge followed by (62\%) had average level of knowledge and $(08 \%)$ had below average level of knowledge

Hence it was concluded that the majority of care takers had average knowledge score on first aid measures regarding domestic accidents among rural area and urban area 
Table 2: Criterion Measure of attitude Score of care takers of Rural Area and Urban Area Children $\mathbf{N}=\mathbf{1 0 0} \mathbf{n}_{\mathrm{r}}=\mathbf{5 0} \mathbf{n}_{\mathbf{u}}=\mathbf{5 0}$

\begin{tabular}{|l|c|c|c|c|}
\hline \multirow{2}{*}{ Level of Attitude } & \multicolumn{2}{|c|}{ Rural area } & \multicolumn{2}{c|}{ Urban area } \\
\cline { 2 - 5 } & (f) & (\%) & (f) & (\%) \\
\hline Strongly agree (38-48) & 00 & 00 & 01 & 02 \\
\hline Undecided (27-37) & 32 & 64 & 39 & 78 \\
\hline Strongly disagree (16-26) & 18 & 36 & 10 & 20 \\
\hline
\end{tabular}

Maximum score: 3

Minimum score: 1

Table 2 depicted the frequency and percentage distribution of level of attitude among caretakers residing in Rural and Urban area. It shows that care takers of rural area $(00 \%)$ had strongly agree about the statements followed by $(64 \%)$ had undecided about the statements, followed by (36\%) had strongly disagree about the statements whereas care takers of urban area $(02 \%)$ had strongly agree about the statements followed by $(78 \%)$ had undecided about the statements and (20\%) had strongly disagree attitude towards first aid management for selected domestic accidents.

Hence it was concluded that the majority of care takers had undecided statements on first aid measures regarding domestic accidents among rural area and urban area.

\section{Discussion}

The aim of study was to compare knowledge level and attitude level on first-aid measures for selected domestic accidents among caretakers of under-five children residing in selected rural and urban areas of District Fatehgarh Sahib, Punjab with a view to develop and distribute an information booklet.

The present study shows that care takers of Rural area $(22 \%)$ had good level of knowledge followed by (74\%) had average level of knowledge, followed by (04\%) had below average knowledge whereas in urban area $(30 \%)$ had good level of knowledge followed by $(62 \%)$ had average level of knowledge and $(08 \%)$ had below average level of knowledge. These findings are consistent with the findings of Thein MM, Lee BW, Bun PY. who conducted a study to assess the knowledge level, attitude level and practices of childhood injuries and their prevention by primary caregivers in Singapore. The study result revealed that primary caregivers had poor knowledge on home accidents and first aid. ${ }^{(5)}$
It shows that care takers of rural area $(00 \%)$ had strongly agree about the statements and(64\%) had undecided about the statements, followed by (36\%) had strongly disagree about the statements regarding domestic accidents whereas care takers of urban area $(02 \%)$ had strongly agree about the statements followed by (78\%) had undecided about the statements and $(20 \%)$ had strongly disagree attitude towards first aid management for selected domestic accidents.

The present study compares the knowledge on first aid measures regarding selected domestic accidents among caretaker of under five children in rural and urban areas. It showed the mean, standard deviation and ' $t$ ' value of knowledge score of care takers regarding selected domestic accidents. The data showed that the mean knowledge score and standard deviation of urban area care takers $(18.0 \pm 4.20)$ was higher than the mean knowledge score of the rural care takers $(17.4 \pm 3.51)$. The calculated ' $t$ ' value of 0.77 was found as statistically non -significant.

This study compared the attitude on first aid measures regarding selected domestic accidents among caretakers of under five children in rural and urban areas. The findingsof study showed the mean, standard deviation and' $t$ ' value of attitude score of care takers regarding selected domestic accidents. The data showed that the mean knowledge score and standard deviation was higher in urban area $(29.3 \pm 3.72)$ as compared to rural care takers $(28.0 \pm 3.37)$. The calculated't' value of 1.80 was found statistically non-significant.

In present study the association between knowledge score of caretakers regarding first aid measures on selected domestic accidents with their demographic variables was seen. The findings of the study showed that there was no significant association of knowledge score with selected demographic variable $(p \leq 0.05)$. i.e.gender, religion, type of family, relation with child, Educational status, Family monthly income, source of information, any type of accident, with knowledge of care takers regarding selected domestic accidents among under -five children in selected area of Distt. Fatehgarh Sahib.

The study find the association between attitudes score on first aid measures regarding selected domestic accidents with their demographic variables. The findings of the study showed that there was not any significant association of following demographic variables age, 
gender, religion, type of family, relation with child, Educational status, Family monthly income, source of information, any type of accident,with attitude of care takers regarding selected domestic accidents among under -five children in selected area of Distt. Fatehgarh Sahib.

\section{Conclusion}

The finding of this study indicates the need of giving more focus on knowledge regarding domestic accidents in rural areas and creating awareness regarding these accidents through information booklets and health education programmes in the community. Although the knowledge score was good in urban area it also needs to improve the knowledge regarding these types of domestic accidents. The above measure will help to reduce these types of domestic accidents among under five children.

Ethical Clearance: Taken from Ethical committee of Desh Bhagat University, Mandi Gobindgarh.

Source of Funding: Self

Conflict of Interest: Nil

\section{References}

1. Clin J A, Izmir H Y. Accidents and mother's measurements in preschool children. 2010; 4(1):1521.

2. SugunaTC.et al., "Women's awareness about domestic accidents among toddlers," International Journal of Development Research. 2015; 5 (03): 3729-3733

3. Park K. Textbook of Preventive and Social Medicine. 20th Edition Jabalpur(India): Banarsidas Bhanot publications, 2009
4. Mizuta R, Fujita H, Osamura T, Kidowaki T, Kiyosawa N. Department of Pediatrics, Kyoto Second Red Cross Hospital, Japan. PMID: 8351984

5. Thein MM, Lee BW, Bun PY.Study to assess the knowledge level, attitude level and practices of childhood injuries and their prevention by primary caregivers, Pubmed.2005; 46 (3): 122-126.

6. BennettLM.Beliefs of adolescent's mothers about parenting and injury prevention. J Pediatric Health Care. 2001 Jul-Aug; 15(4):194-199.

7. Eldosoky RSH. Home related injuries of children: knowledge, attitudes and practice about first aid among rural mothers. East Mediter Health J. 2012;18(10):1021-7

8. Kamala B, Wilson ML, Hasselberg M .Pattern of childhood falls in a low-income setting, Department of Public Health. 2011.

9. Mahalakshmy T, Dongre AR, Kalaiselvan G. Epidemiology of Childhood Injuries in Rural Puduchery .Department of Community Medicine, J Pediatric. 2011 Jan 4.

10. Bhavaneswary $\mathrm{S}$ et al. Prevention of Burn Injury. 2010:312-318

11. Click DC, Graves PE, Kronerfeldf JJ, Jackson K. Safety hazards in household with young children, $\mathrm{J}$ Pediatr Psychol. 2000; 18 (1): 115-31.

12. Bhavaneswary $\mathrm{S}$ et al. Prevention of Burn Injury. $2008: 312-318$

13. Chaudhari V, Srivastava, R, Moitra, M. and Desai, V.Risk of Domestic Accidents of under Five Children. The Internet Journal of Family Practice.2008; 7.

14. SibelE, SukranS. Department of Home Economics. The Turkish Journal of Paediatrics .2006; 48: 56-62

15. Beivens TM. Prevention of Home Accidents. The knowledge and practice of mother prevention of burn between 9 months 9 years .2006:312-318. 